\title{
Therapeutic Index
}

National Cancer Institute

\section{Source}

National Cancer Institute. Therapeutic Index. NCI Thesaurus. Code C18223.

The difference between the concentration at which clinical benefit is seen and that at which toxicity occurs. It is expressed as the range between the median effective dose and the median toxic dose.T he larger the therapeutic index the safer a drug is. 